\title{
A Study of the Magnetospheric Micropulsations Pc5 and Pc6 Using Magnetic Stations at Low Latitude Northern Region of Brazil and Ascension Island during Magnetic Stormed Magnetospheric Plasma
}

\author{
Vinícius José Oliveira Werneck de Carvalho ${ }^{1 *}$, Luiz Carlos de Carvalho Benyosef ${ }^{1}$, \\ Altair Souza de Assis ${ }^{2}$ \\ ${ }^{1}$ Departamento de Geofísica, Observatório Nacional, Rio de Janeiro, Brazil \\ ${ }^{2}$ Departamento de Matemática Aplicada, Universidade Federal Fluminense, Niterói, Brazil \\ Email: *viniciusonrj@gmail.com
}

How to cite this paper: de Carvalho, V.J.O.W., de Carvalho Benyosef, L.C. and de Assis, A.S. (2019) A Study of the Magnetospheric Micropulsations Pc5 and Pc6 Using Magnetic Stations at Low Latitude Northern Region of Brazil and Ascension Island during Magnetic Stormed Magnetospheric Plasma. Journal of Electromagnetic Analysis and Applications, 11, 41-54. https://doi.org/10.4236/jemaa.2019.114004

Received: April 26, 2019

Accepted: April 27, 2019

Published: April 30, 2019

Copyright ( 2019 by author(s) and Scientific Research Publishing Inc. This work is licensed under the Creative Commons Attribution International License (CC BY 4.0).

http://creativecommons.org/licenses/by/4.0/

(c) (i) Open Access

\begin{abstract}
In general, micropulsation is generated by the free energy within the magnetosphere, which is mainly caused by the magnetosphere-solar wind interactions and/or magnetic field reconnections in the magnetospheric tail. In this article, we studied the types of low-frequency magnetospheric micropulsations Pc5 and Pc6 (1 - $6 \mathrm{mHz})$, during three magnetic storms, using ground magnetic observations. One of the main motivations of this study was to produce scientific knowledge on the subject in order to fill knowledge gaps in this region, collaborating with existing bibliographies. The data were recorded in a series of six Brazilian stations close to the Dip Equator (dip = 0), with using data from the Ascension Island observatory. Pulse trains were found to occur simultaneously with almost identical waveforms, with significant amplitude increase near magnetic local noon. Amplitude spectra showed a clear similarity in all equatorial seasons. The results obtained were compared with studies performed in regions with similar low latitudes. The possible mechanisms that induced these micropulsations and the peculiarities presented by these data were also discussed in this article.
\end{abstract}

\section{Keywords}

Magnetospheric Micropulsations, Electrojet Equatorial, Alfvén Waves, Geomagnetic Storms

\section{Introduction}

Geomagnetic storm conditions are characterized by an intensification of equa- 
torial "ring" current (at 2 - 7 Earth radii above the ground) and an expansion of the auroral oval region to lower latitudes [1]. Disturbances caused by geomagnetic storms enhance the appearance of geomagnetic pulsations or ultra-low frequency waves (ULF). Most of the geomagnetic pulsations appear as magnetospheric hydromagnetic waves (Alfvén) thought to be generated by the Kelvin-Helmholtz instability process as a result when one magnetospheric plasma is transmitted over another [2]. These pulsations are transported to the auroral latitudes along the lines of the magnetospheric field and, thus, exhibit equivalent behaviors in conjugate regions.

ULFs having the period range of 2.5 to 20 minutes $(1-7 \mathrm{mHz})$ are classified as continuous pulsations of type 5 and 6 (Pc 5-6). The beautiful sinusoidal shape of the amplitude is often considered as a result of the resonance effect between a conjugate field line, assuming that reflection occurs in the northern and southern ionosphere. The mechanism of their generation apparently corresponds to field line resonances driven by magnetosphere cavity or waveguide modes [3] [4]. Pc5-6 are generally observed at ground stations located in polar latitudes [5], however, are also observed at low latitudes [6].

In this article, we presented a comparative investigation of the ULF (Pc5-6) geomagnetic pulses detected in six Brazilian terrestrial stations and in the Ascension Island observatory (United Kingdom). We illustrated our studies with the sudden onset of the storm (SSC) occurred on September 9 and September 26, 2011, at 11:00 UT and on the 17th at 3:00 UT. To examine the characteristics of the magnetic pulses, we used digital filtering methods (bandpass) and Wavelet. For this, we used the time series formed by the horizontal component $\mathrm{H}$ of the geomagnetic field.

This study aims to fill a knowledge gap by collaborating with previous research and scientific studies in this particular region.

\section{Data Sets}

The investigation is based on digitized one-second sampling geomagnetic data on the latitudinal array of six Brazilian ground magnetic stations mounted perpendicular to the Dip Equator and the Ascension Island observatory, during three complete days of moderate storms on 09, 17 and 26, of September 2011 Figure 1. The coordinates and schematic presentation of the station's locations are given in Figure 2 and Table 1. Only one station Juaba (JUA) is situated under the dip equator $(\operatorname{dip}=0)$. Two stations Tatuoca $(\mathrm{TTB})$ and Goianésia (GOI) are located at few degrees away from the dip $=0$.

The data were recorded using the Lemi-417 system, produced on the basis of fluxgate sensor. To illustrate our study, we took the data corresponding to 9, 17 and 26 September 2011, in order to examine the pulsations associated with a sudden onset of storm (SSC) occurred at 11:00 UT (days 9 and 26 ) and 03:00 (day 17).

\section{Results}

Figures 3-5 show the geomagnetic diurnal variations in September in all the 


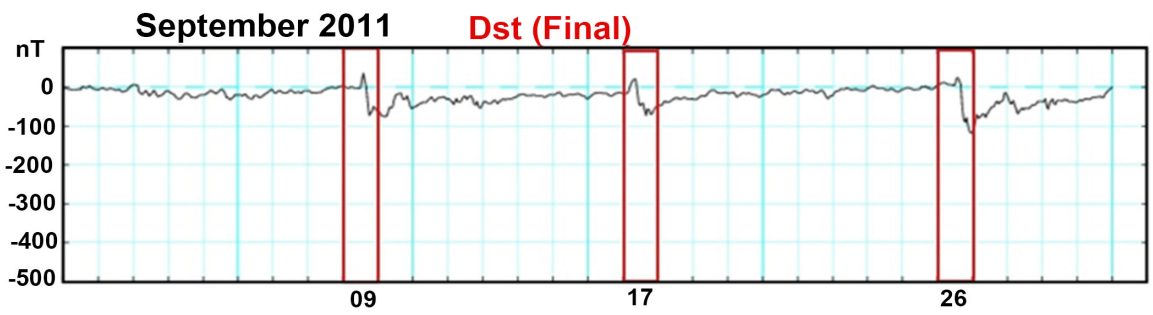

Figure 1. Dst geomagnetic index for the month of September 2011. Figure edited from http://wdc.kugi.kyoto-u.ac.jp/dst_final/201109/.

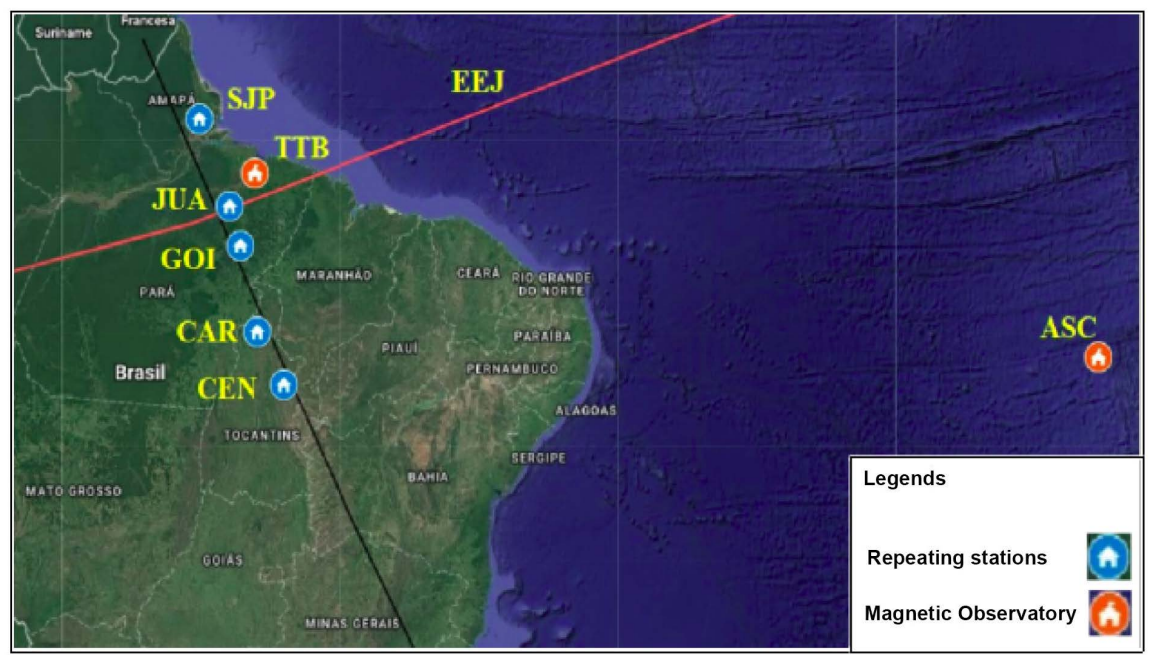

Figure 2. Schematic map of stations' location.

Table 1. The geographic and geomagnetic locations of all stations.

\begin{tabular}{cccccc}
\hline Station Name & Code & Lat. (G.G) & Long. (W) (G.G) & Lat. (G.M) & Long. (E) (G.M) \\
\hline São Joaquim do Pacuí & SJP & 0.81 & 50.75 & 10.04 & 21.89 \\
Tatuoca & TTB & -1.20 & 48.50 & 7.88 & 24.03 \\
Juába & JUA & 2.38 & 49.55 & 6.78 & 22.89 \\
Goianésia & GOI & -3.83 & 49.08 & 5.83 & 23.26 \\
Carmolândia & CAR & -7.06 & 48.38 & 2.06 & 23.73 \\
Centenário & CEN & -8.98 & 47.20 & 0.08 & 24.77 \\
Ascension Island & ASC & -7.94 & 14.35 & -2.55 & 57.19 \\
\hline
\end{tabular}

regions used. On day 17 , the stations where we can observe a different pattern in relation to days 9 and 26, were possibly influenced by particular conditions in the electronic density in the EEJ, thus its pattern was changed in relation to other days.

The analyzed Pc5-6 geomagnetic pulsations at low and equatorial latitudes look like isolated simultaneous wave packets at every station. Figures 6-8 show the $1.6-6.7 \mathrm{mHz}$ filtered pulsations at five near dip equator stations (SJP, TTB, GOI, CAR and CENT) and JUA (color red) under the Electrojet (EEJ) in the interval 0 - 24 UT. The pulsations occur as individual simultaneous wave packets with similar appearance over the whole range of longitudes. 


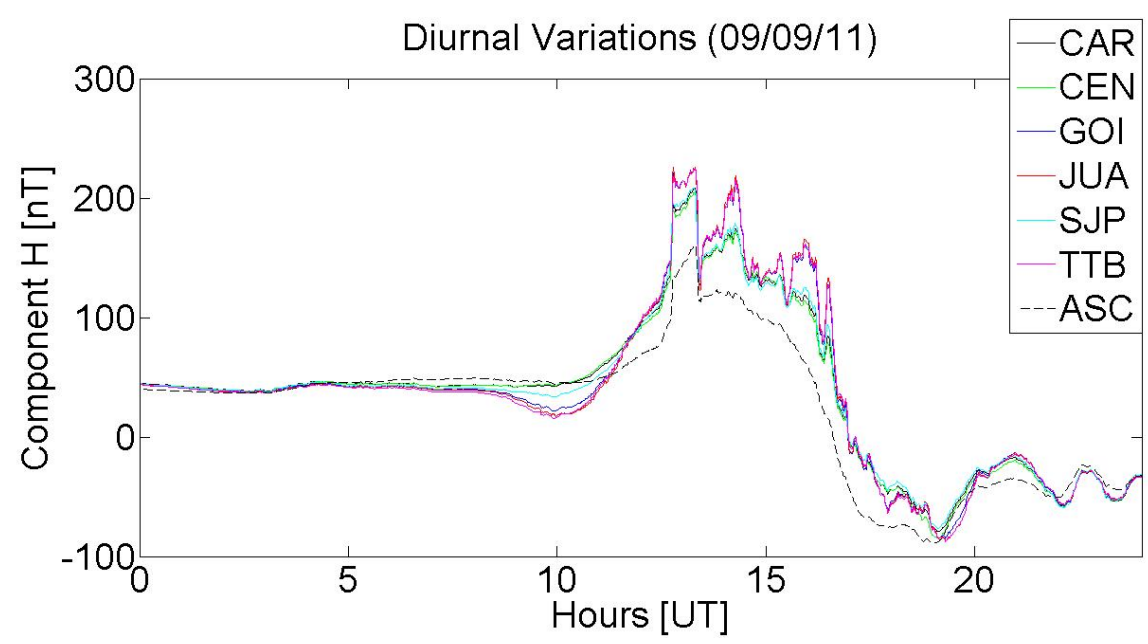

Figure 3. Diurnal variation in component $\mathrm{H}$ between at the six longitudinal sectors on September 9, 2011, at 00-24 UT.

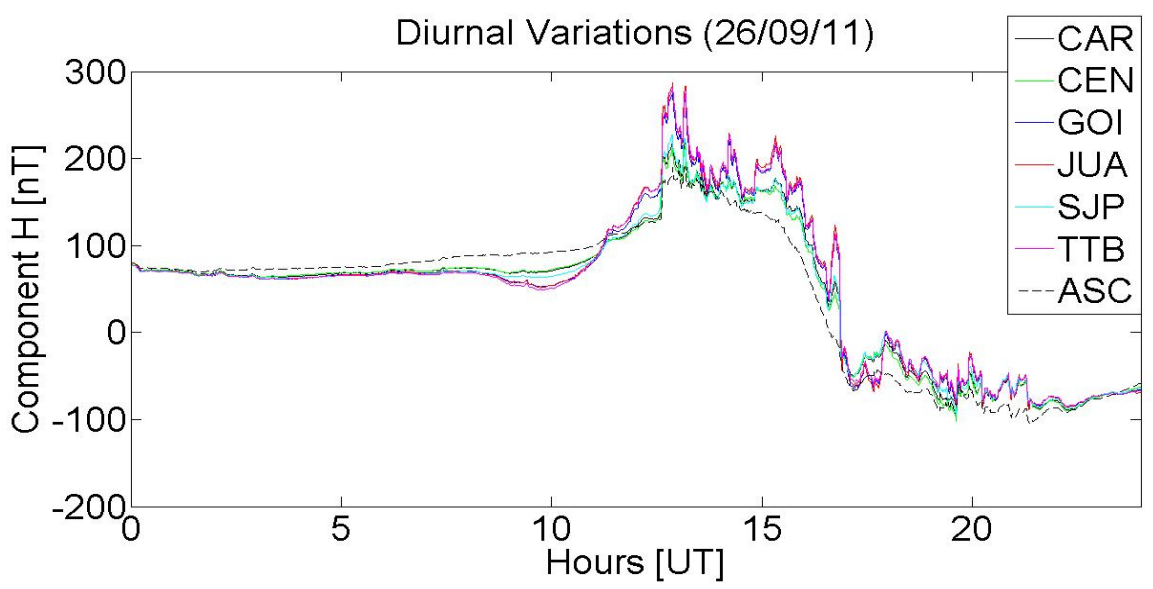

Figure 4. Diurnal variation in component $\mathrm{H}$ between at the six longitudinal sectors on September 17, 2011, at 00-24 UT.

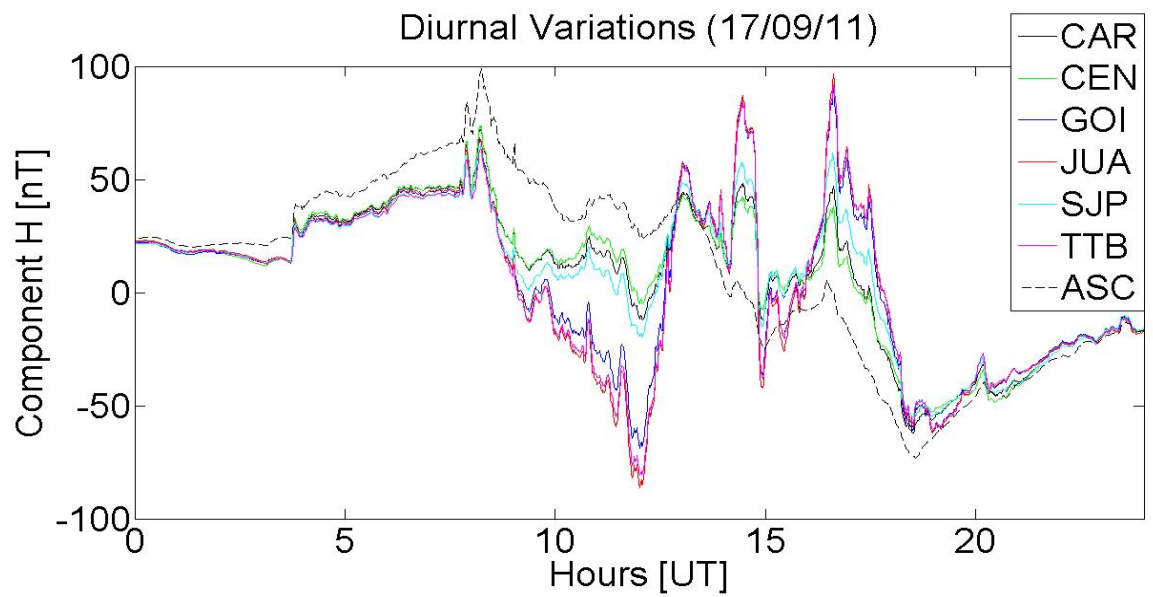

Figure 5. Diurnal variation in component $\mathrm{H}$ between at the six longitudinal sectors on September 26, 2011, at 00-24 UT. 


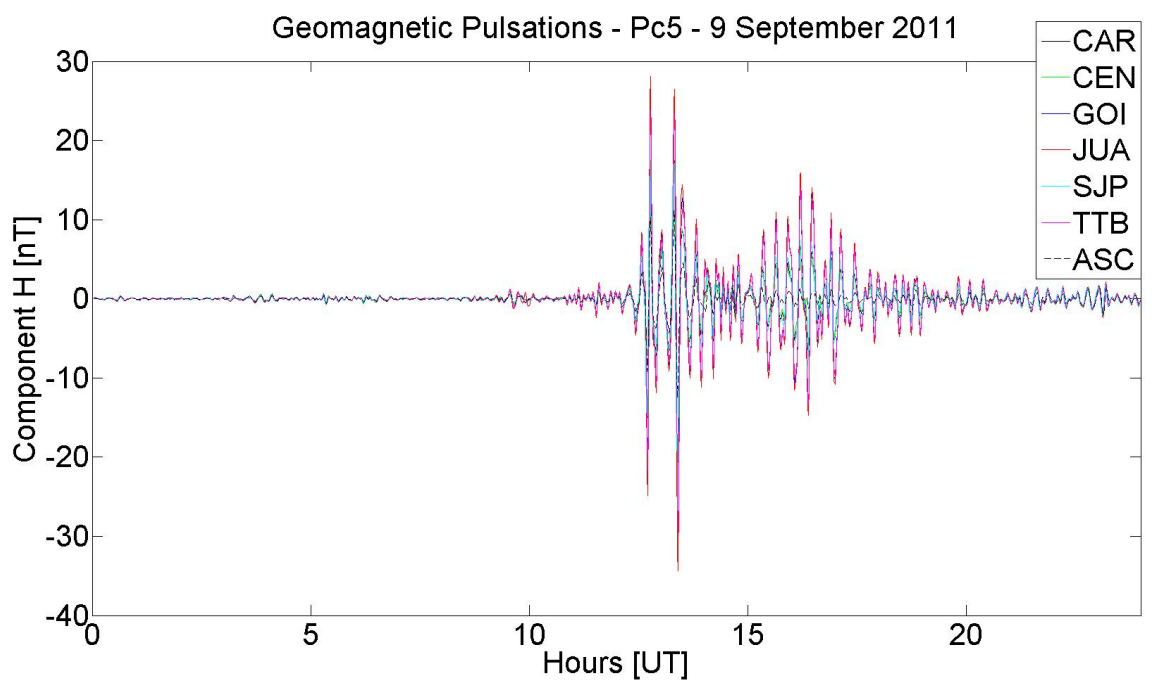

Figure 6. Filtered pulsations (Pc5) at six stations, on 9 September 2011.

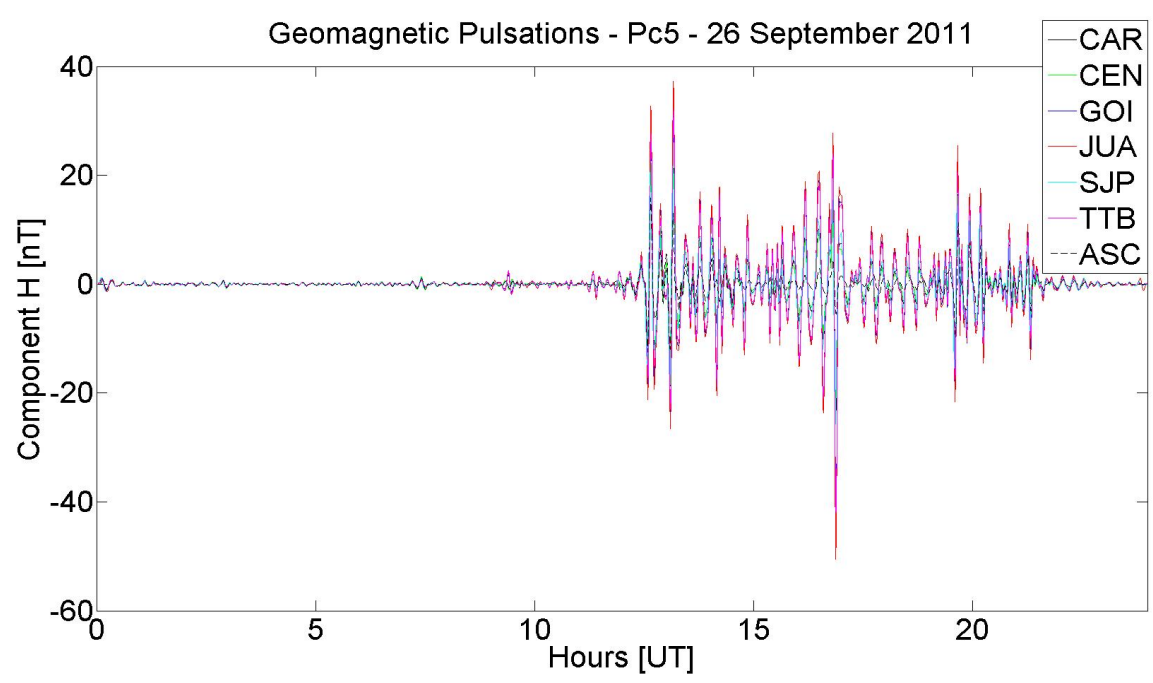

Figure 7. Filtered pulsations (Pc5) at six stations, on 26 September 2011.

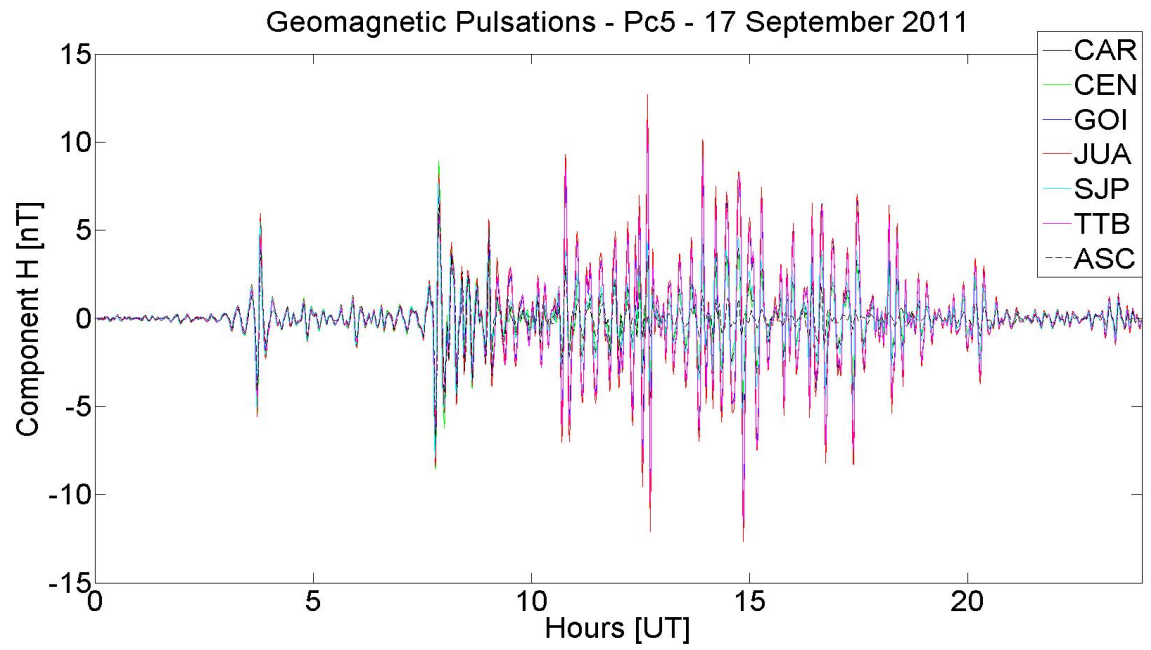

Figure 8. Filtered pulsations (Pc5) at six stations, on 17 September 2011. 
Figures 3-5 show the morphological similarities, with $\mathrm{H}$ reaching maximum amplitude around local noon. Probably the latitudinal proximity between the stations is producing such similarity. However, near the dip $=0$, TTB and GOI, present a marked depression at $10 \mathrm{UT}$, JUA located exactly under the dip $=0$, has a greater depression in relation to the others. This characteristic was also observed in studies known by the Equatorial Electrojet (EEJ).

On the 9th (Figure 6), the wave trains were recorded between 13 and 18 UT, decreasing their intensity at dusk. The same behavior could be seen on day 26 (Figure 8), except 17th (Figure 7), where the micropulsations were recorded uniformly throughout the day and with well-defined wave packets and with a similarity between stations.

Figures 9-11 show the Pc6 pulses recorded at the six stations on days 9, 17 and 26. As in the Pc5 pulses, the Pc6 wave trains also showed the same behaviors.

The amplitude of the wave packet observed between 0 - 24 UT in all stages did not show large amplitudes only in the local half day, but also in the afternoon and in the evening. This fact demonstrates that the enhancement of the $\mathrm{H}$ component of the equatorial pulse intensity Pc5-6 is not confined to hours near the local noon.

Figures 12-17 show the energy spectral analysis with wavelets of the $\mathrm{H}$ component, of geomagnetic pulsations in the period Pc5-6 (2 - $20 \mathrm{~min})$. On day 9 pulsations of type Pc5-6 were recorded in the period between 12 UT and 18 UT in all Brazilian stations. The pulsations were observed almost simultaneously in time, presenting marked energy levels in the stations near the EEJ. In the ASC station, the Pc5-6 began in the same period as in the Brazilian stations but were observed until 14UT, presenting low energy levels.

On day 17, pulsations were recorded throughout the 24 hours, the Brazilian stations continued to present temporal similarity with the JUA and GOI stations presenting higher energy levels in comparison with the stations farthest from the

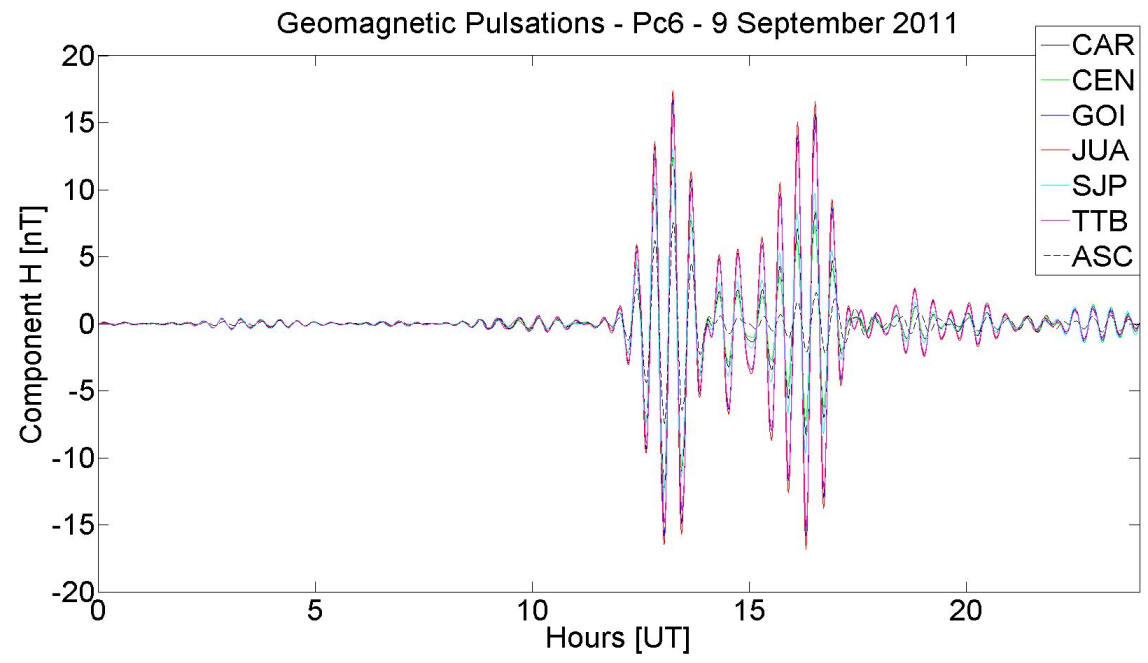

Figure 9. Filtered pulsations (Pc6) at six stations, on 9 September 2011. 


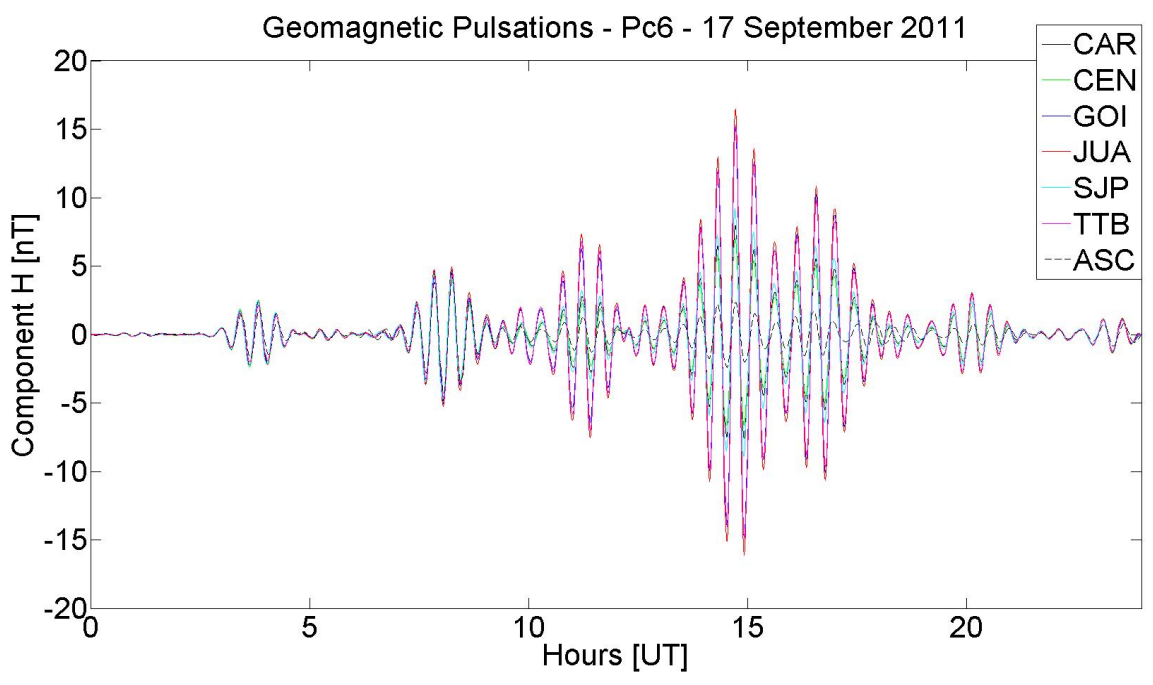

Figure 10. Filtered pulsations (Pc6) at six stations, on 17 September 2011.

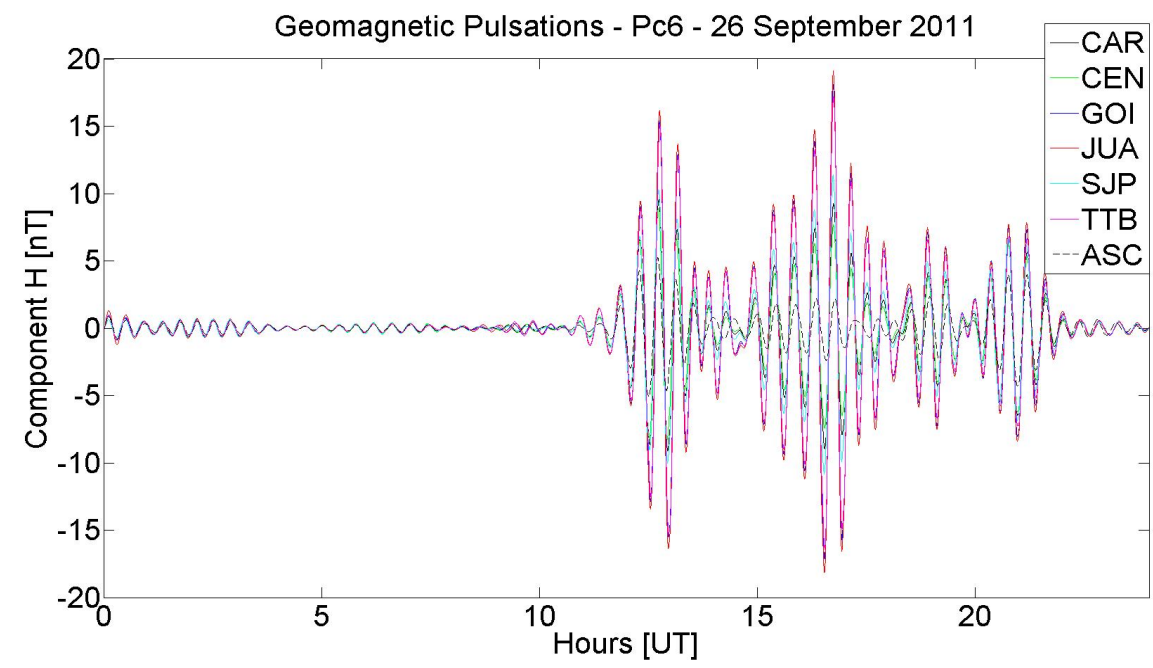

Figure 11. Filtered pulsations (Pc6) at six stations, on 26 September 2011.

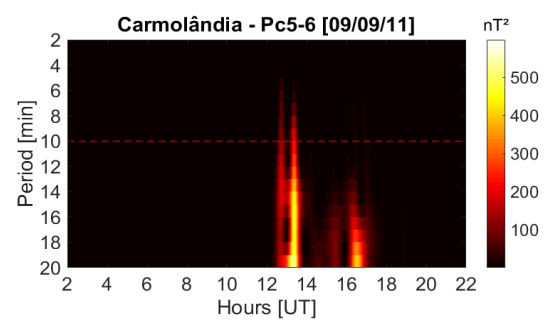

Goianésia - Pc5-6 [09/09/11]

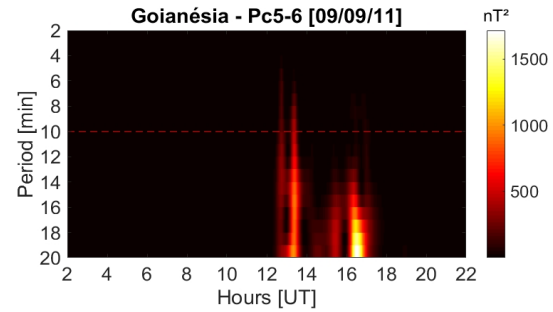

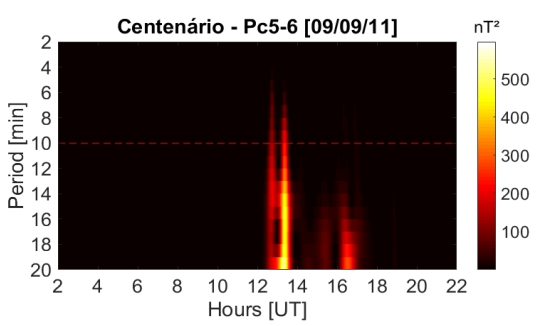

Juába - Pc5-6 [09/09/11]

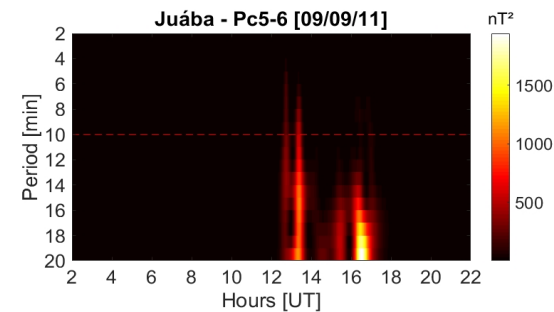

Figure 12. Pc5 energy spectra (2 - $10 \mathrm{~min})$ and Pc6 (10 - $20 \mathrm{~min})$ in the H component, on 09-09-11, at the CAR, CEN, GOI and JUA stations. 

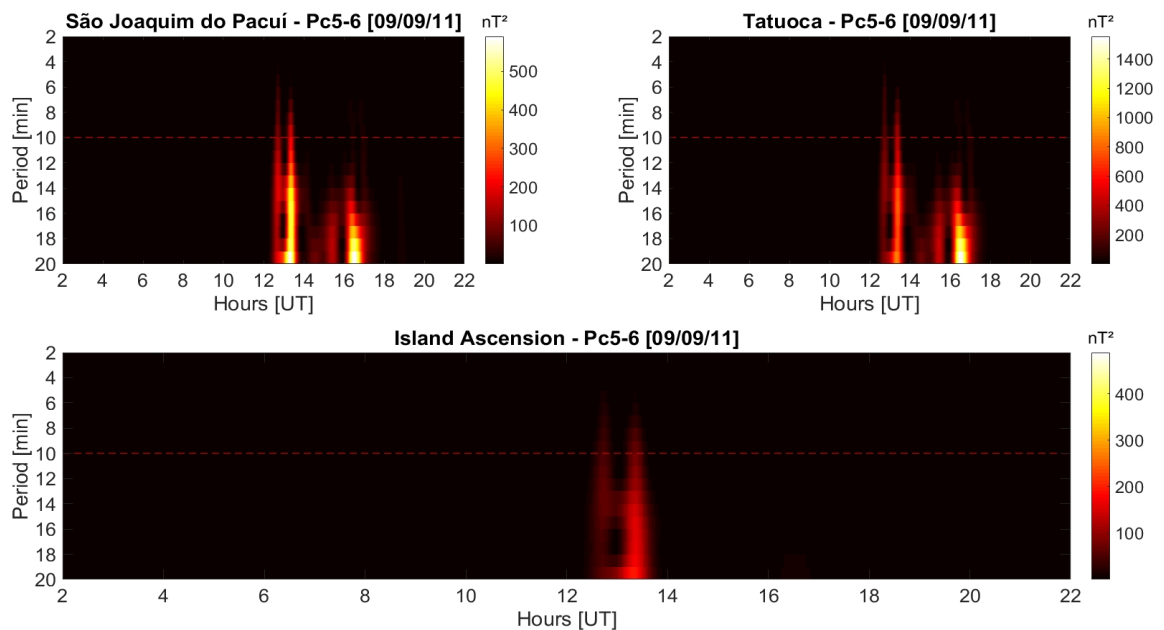

Figure 13. Pc5 energy spectra (2 - $10 \mathrm{~min})$ and Pc6 (10 - $20 \mathrm{~min})$ in the H component, on 09-09-11, at the SJP, TTB and ASC stations.
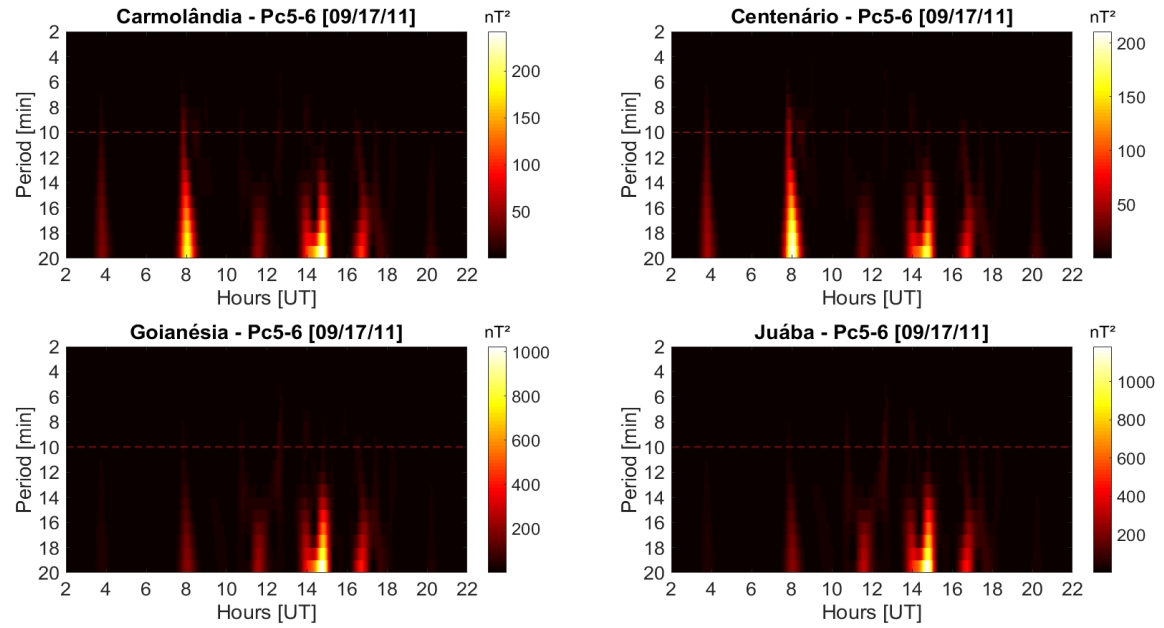

Figure 14. Pc5 energy spectra (2 - $10 \mathrm{~min})$ and Pc6 (10 - $20 \mathrm{~min})$ in the H component, on 09-17-11, at the CAR, CEN, GOI and JUA stations.
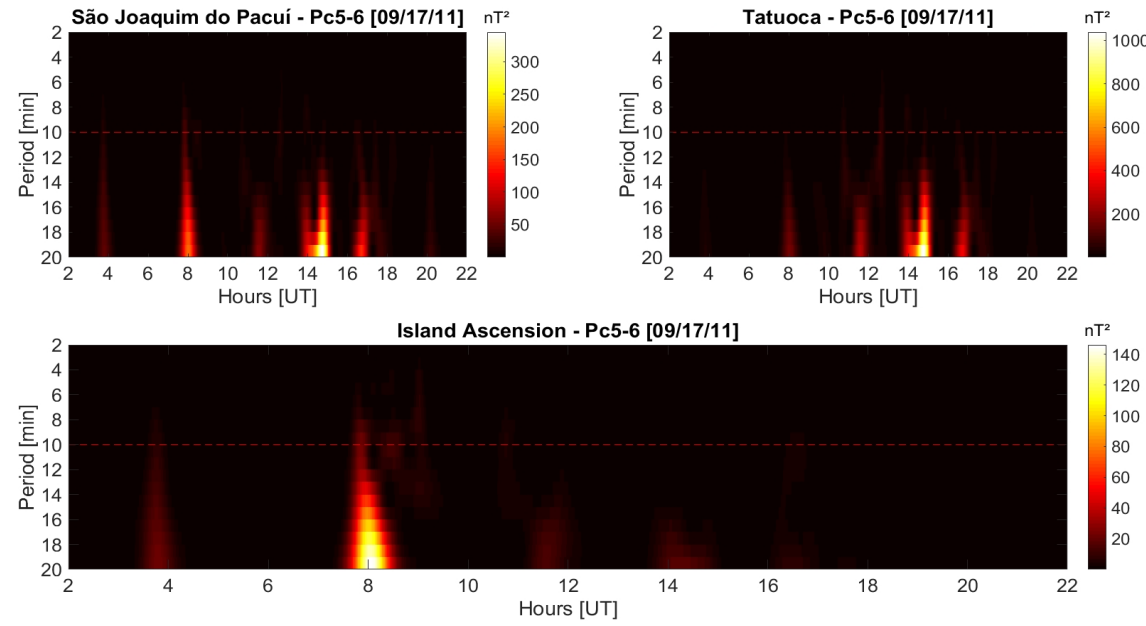

Figure 15. Pc5 energy spectra (2 - $10 \mathrm{~min})$ and Pc6 (10 - $20 \mathrm{~min})$ in the H component, on 09-17-11, at the SJP, TTB and ASC stations. 

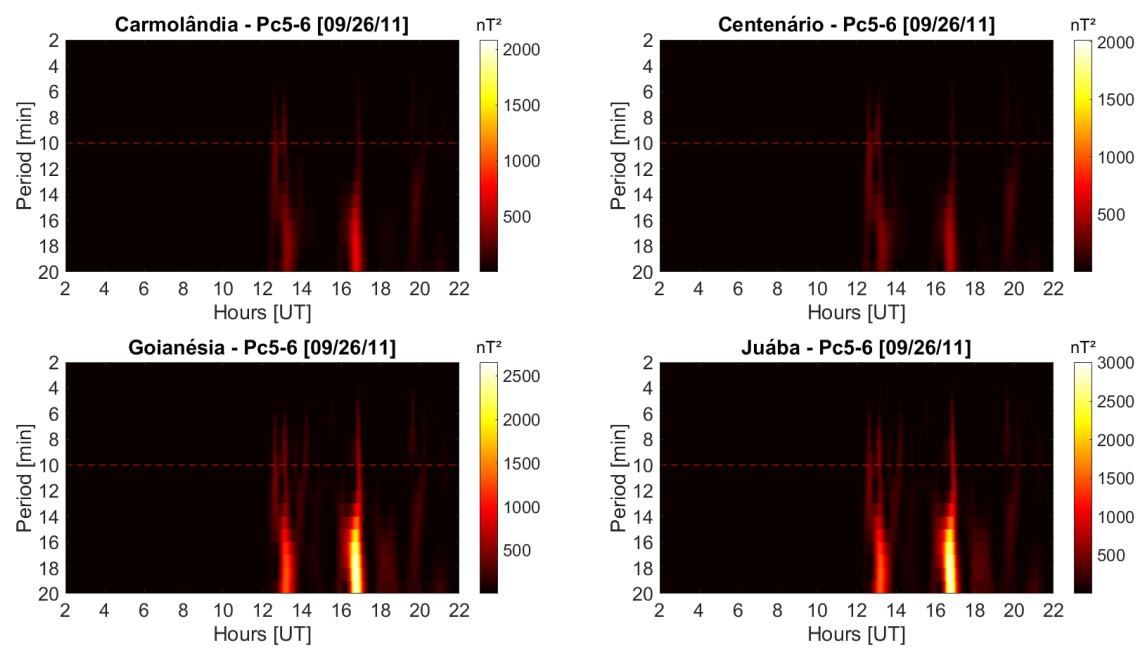

Figure 16. Pc5 energy spectra (2 - $10 \mathrm{~min})$ and Pc6 (10 - $20 \mathrm{~min})$ in the $\mathrm{H}$ component, on 09-26-11, at the CAR, CEN, GOI and JUA stations.
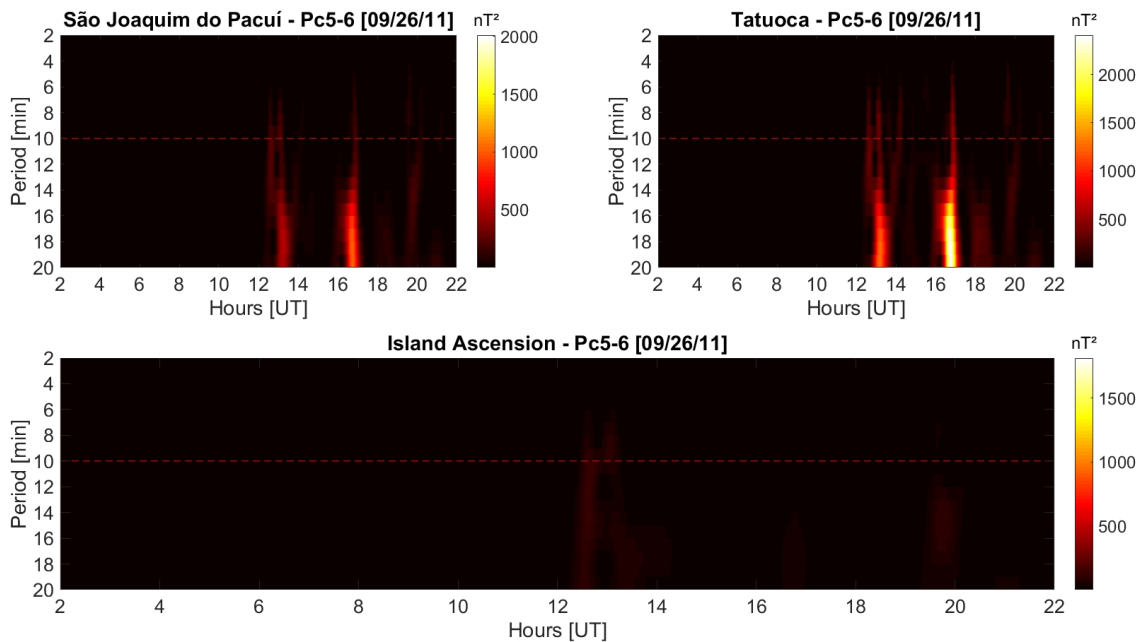

Figure 17. Pc5 energy spectra (2 - $10 \mathrm{~min})$ and Pc6 (10 - $20 \mathrm{~min})$ in the $\mathrm{H}$ component, on 09-26-11, at the SJP, TTB and ASC stations.

EEJ. The 8 UT at the ASC station recorded marked energy in the Pc6 pulse range.

For day 26, the pulsations were only observed from 13 UT in the Brazilian stations, extending until 20 UT. However, in the ASC station, almost no sign of the pulsations was recorded, presenting very low energies in the analyzed period. Due to the strong magnetic storm that occurred on the 26th, a high amount of energy was observed in the pulsations recorded in the Brazilian stations and in the ASC station.

One of the most important characteristics of heartbeats observed on the surface, is its polarization. The data of the SJP, TTB and CEN stations were processed because they are the stations to the South, dip $=0$ and more to the North of the EEJ respectively. For this analysis, was chosen the 09-09-2011, being the geomagnetically most disturbing day in the month of September. The 
results can be seen in Figures 18-20.

The results obtained through the hodograms show that the direction of propagation (polarization) of the MHD wave in the stations is on the left (left-handed). With this result, we can affirm that the pulses Pc5-6 recorded in the Brazilian stations are of an alpha nature.

The results presented for the polarization of the wave observed in Brazilian stations are in line with other studies carried out [7] [8]. The alpha waves propagate in the anti-solar direction on the flanks, producing waves in the magnetopause. The suggested theories to explain these MHD waves are: surface wave generation by Kelvin-Helmholtz instabilities $(\mathrm{KH})$ in the magnetopause, surface wave generation in the magnetopause due to the solar wind pressure pulses in the magnetic sheath and localized magnetic anomalies, such that the processes of flow transfer events or intermittent reconnections may be associated with waves in the magnetopause [9] [10] [11]. Due to the location of the Brazilian stations (range of influence of the EEJ) and the nature of the pulsations observed, it is concluded that the most adequate theory to explain the waves is $\mathrm{KH}$ allied to localized magnetic anomalies.

\section{Conclusion}

Based on the results and discussions presented, it was observed that the diurnal variation in the Brazilian stations presented changes caused by changes in ionospheric conductivity, which occurred in the equatorial region, during the 24

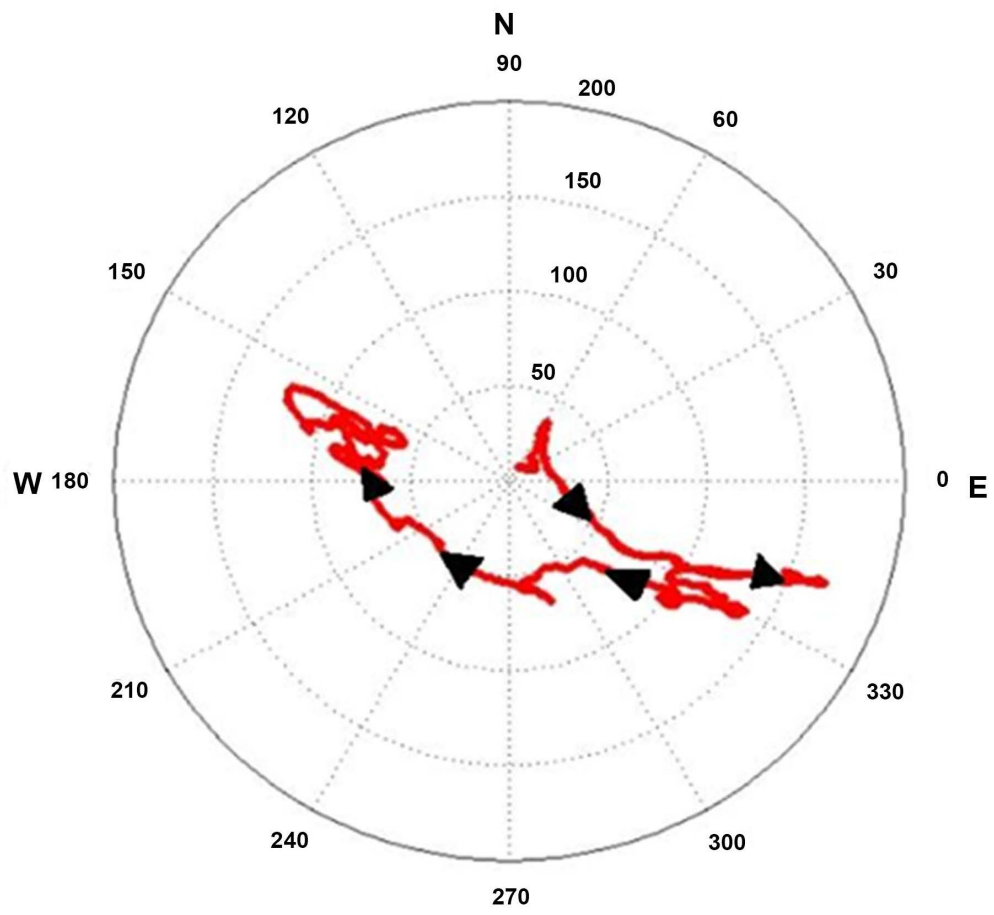

S

Figure 18. Polarization hodogram, indicating the direction of disturbance of the MHD wave in the SJP station 09-09-11. 


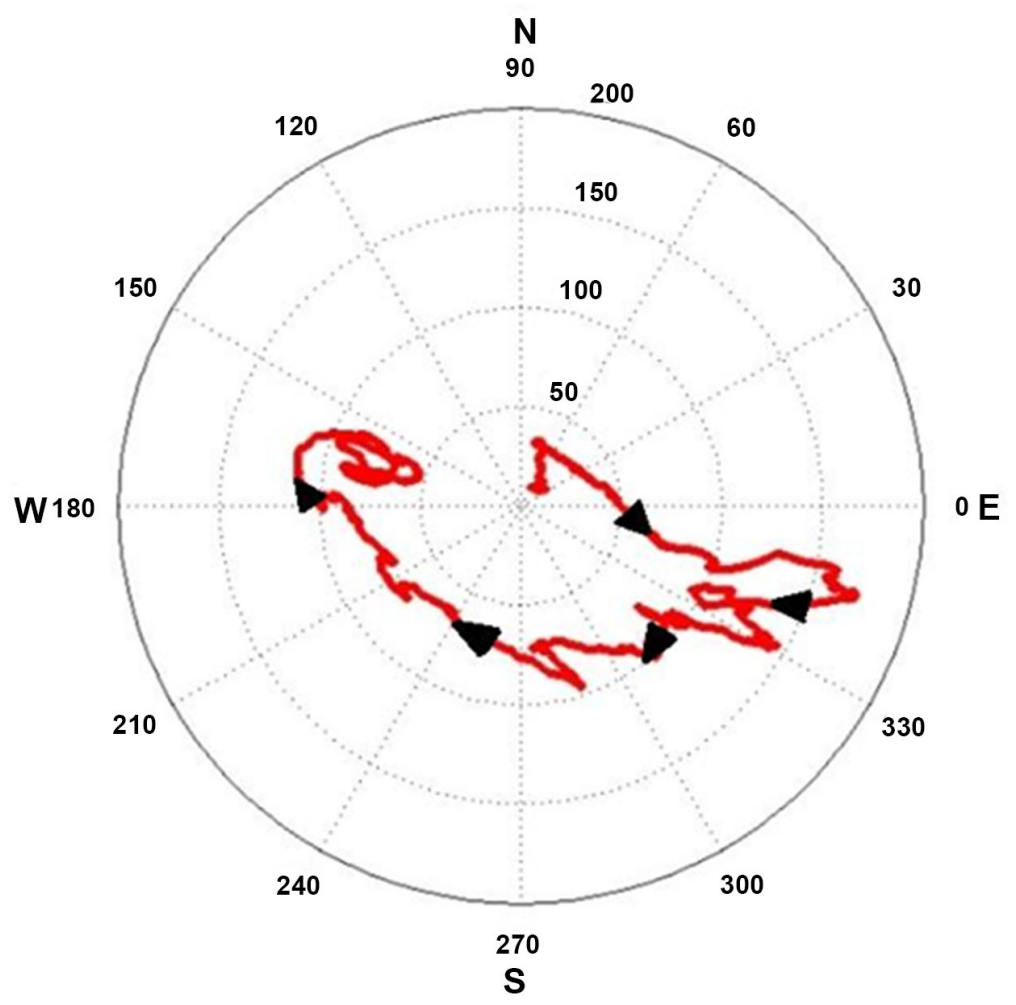

Figure 19. Polarization hodogram, indicating the direction of disturbance of the MHD wave in the TTB station 09-09-11.

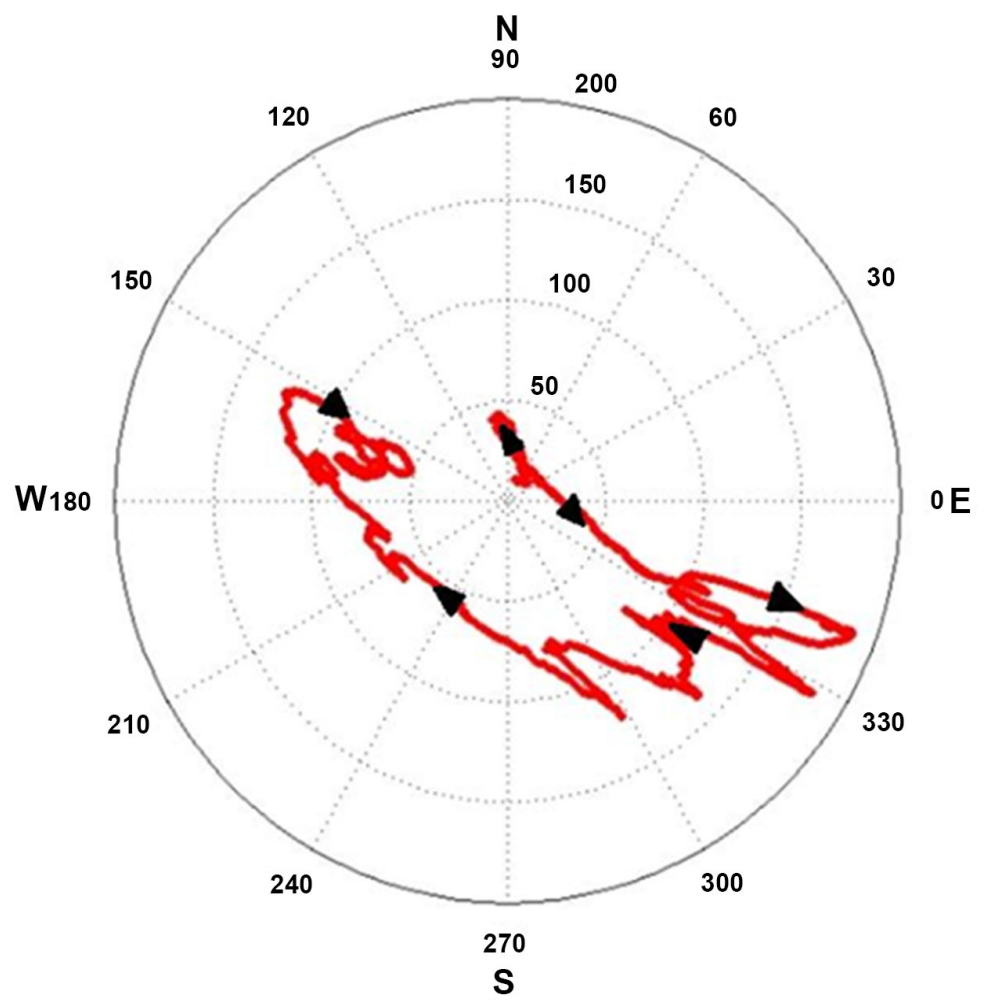

Figure 20. Polarization hodogram, indicating the direction of disturbance of the MHD wave in the CEN station 09-09-11. 
hour period, in magnetically calm and disturbed days, which was not observed at the ASC station. The JUA station ( $\operatorname{dip}=0)$, presented higher values in the variation of the $\mathrm{H}$ component in relation to the other stations, and results that were in agreement with previous studies [12] [13].

The results of the filtering and the wavelet analysis presented temporal and morphological similarity between the Brazilian stations, being distinguished only by the amplitudes. The filtrations showed well-defined wave packets, mainly in the Pc6 range. The ASC station also showed some temporal similarity in the repository of the pushes, but weaker in energy. The morphological similarity in the Brazilian stations, both in the diurnal variation and in the filtrations, is probably due to the latitudinal approximation and to the phenomenon known as conjugated points (phenomena observed simultaneously at both ends of a magnetic field line). This similarity can also be explained because they have the same generating source [14] [15] [16].

Figures 12-17 show an increase in the spectral energy of the pulsations under different levels of geomagnetic storm, especially in the vicinity of the EEJ. The increase in geomagnetic phenomena in the EEJ region (both in number and intensity) is probably directly related to the influence of Cowling conductivity effects (EEJ) [17]. In these regions several atmospheric phenomena occur due to concentrations of particles in the geomagnetic field, however, the mechanisms of these effects are not yet fully understood.

Our results also showed that Pc5-6 were almost not recorded in the ASC observatory, presenting low energy levels, even in days of magnetic storms. A possible hypothesis of this effect is that the region is little reactive to this type of heartbeat, possibly because it is outside the influence of the EEJ, as reported in similar works [18] [19] [20].

The TTB, JUA, and GOI stations presented considerable spectral energy values, possibly due to the extra ionization in the E layer of the ionosphere, which would increase the conductivity in and around the EEJ.

Thus, it is concluded that both the instabilities generated in the pulsations and their surface observations may be directly related to the influence of the EEJ and AMAS in the studied regions. The results described so far and the polarization analyzes have proved that the nature of micropulsations recorded in the surface stations of this thesis is torsional (polarized on the left). They have transverse propagation mode along the magnetic field line. Due to the nature of the MHD waves being torsional and by the locality of the studied stations, it is also concluded that the mechanism of MHD wave generation is influenced by Kelvin-Helmholtz instabilities in the magnetopause and localized magnetic anomalies, transmitted by waveguides, and in fact, also observed in previous studies [21] [22] [23]. The methodology used in the data analysis process was of fundamental importance in the identification of the events, as well as in the determination of the spectral frequencies, power spectrum estimation, energy analysis and signal polarization parameters. 


\section{Acknowledgements}

One of the authors, Vinicius Wernek, would like to thank the REBOM project team and CAPES for financial support.

\section{Conflicts of Interest}

The authors declare no conflicts of interest regarding the publication of this paper.

\section{References}

[1] Gonzalez, W.D., Joselyn, J.A., Kamide, Y., Kroehl, H.W., Rostoker, G., Tsurutani, B.T. and Vasyliunas, V.M. (1994) What Is a Geomagnetic Storm. Journal of Geophysical Research: Space Physics, 99, 5771-579. https://doi.org/10.1029/93JA02867

[2] Campbell, K.W. (1997) Empirical Near-Source Attenuation Relationships for Horizontal and Vertical Components of Peak Ground Acceleration, Peak Ground Velocity, and Pseudo-Absolute Acceleration Response Spectra, Seismological. Seismological Research Letters, 68, 154-179. https://doi.org/10.1785/gssrl.68.1.154

[3] Harrold, B.G. and Samson, J.C. (1992) Standing ULF Modes of the Magnetosphere: A Theory. Geophysical Research Letters, 19, 1811-1814. https://doi.org/10.1029/92GL01802

[4] Samson, J.C., Harrold, B.G., Ruohoniemi, J.M., Greenwald, R.A. and Walker, A.D.M. (1992) Field Line Resonances Associated with MHD Waveguides in the Magnetosphere. Geophysical Research Letters, 19, 441-444, https://doi.org/10.1029/92GL00116

[5] Ziesolleck, C.W.S. and McDiarmid, D.R. (1994) Auroral Latitude Pc5 Field Line Resonances: Quantized Frequencies, Spatial Characteristics and Diurnal Variation. Journal of Geophysical Research: Space Physics, 99, 5817-5830. https://doi.org/10.1029/93JA02903

[6] Lilley, F.E.M. and Bennett, D.J. (1973) Micropulsations Recorded by an Array of Magnetic Variometers. Journal of Geophysical Research, 78, 1603-1607. https://doi.org/10.1029/JA078i010p01603

[7] Anderson, B.J., et al. (1994) An Overview of Spacecraft Observations of $10 \mathrm{~s}$ to $600 \mathrm{~s}$ Period Magnetic Pulsations in the Earth's Magnetosphere. Solar Wind Sources of Magnetospheric Ultra-Low-Frequency Waves, 81, 25-43. https://doi.org/10.1029/GM081p0025

[8] Cahill, L.J. and Winckler, J.R. (1992) Periodic Magnetopause Oscillations Observed with the GOES Satellites on March 24, 1991. Journal of Geophysical Research: Space Physics, 97, 8239-8243. https://doi.org/10.1029/92JA00433

[9] Hasegawa, A., Tsui, K.H. and Assis, A.S. (1983) A Theory of Long Period Magnetic pulsations: 3. Local Field the Line Oscillations. Geophysical Research Letters, 10, 765-767. https://doi.org/10.1029/GL010i008p00765

[10] Pathan, B.M., Kleimenova, N.G., Kozyreva, O.V., Rao, D.R.K. and Asinkar, R.L. (1999) Equatorial Enhancement of Pc5-6 Magnetic Storm Time Geomagnetic Pulsations. Earth, Planets and Space, 51, 959-964. https://doi.org/10.1186/BF03351566

[11] Chen, L. and Hasegawa, A. (1974) A Theory of Long-Period Magnetic Pulsations: 1. Steady State Excitation of Field Line Resonance. Journal of Geophysical Research, 79, 1024-1032. https://doi.org/10.1029/JA079i007p01024

[12] Chisham, G. and Mann, I.R. (1999) A Pc5 ULF Wave with Large Azimuthal Wave- 
number Observed within the Morning Sector Plasmasphere by Sub-Auroral Magnetometer Network. Journal of Geophysical Research, 104, 14717-14727. https://doi.org/10.1029/1999JA900147

[13] Kitamura, T.I., Saka, O., Shimoizzumi, M., Tachihara, H., Oguti, T., Araki, T., Sato, N., Ishitsuka, M., Veliz, O. and Nyobe, J.B. (1988) Global Mode of Pi2 Waves in the Equatorial Regions-Difference of Pi2 Mode between High and Equatorial Latitudes. Journal of Geomagnetism and Geoelectricity, 40, 621-634. https://doi.org/10.5636/jgg.40.621

[14] Kivelson, M.G. and Southwood, D.J. (1986) Coupling of Global Magnetospheric MHD Eigenmodes to Field Line Resonances. Journal of Geophysical Research: Space Physics, 91, 4345-4351. https://doi.org/10.1029/JA091iA04p04345

[15] Lanzerotti, L.J. and Tartaglia, N.A. (1972) Propagation of a Magnetospheric Compressional Wave to the Ground. Journal of Geophysical Research, 77, 1934-1940. https://doi.org/10.1029/JA077i010p01934

[16] Mann, I.R., Chisham, G. and Bale, S.D. (1998) Multisatellite and Ground-Based Observations of a Tailward Propagating Pc5 Magnetospheric Waveguide Mode. Journal of Geophysical Research: Space Physics, 103, 4657-4669. https://doi.org/10.1029/97JA03175

[17] Olson, J.V. and Rostoker, G. (1978) Longitudinal Phase Variations of PC4-5 Micropulsations. Journal of Geophysical Research: Space Physics, 83, 2481-2488. https://doi.org/10.1029/JA083iA06p02481

[18] Pu, Z.-Y. and Kivelson, M.G. (1983) Kelvin-Helmholtz Instability at the Magnetopause: Energy Flux into the Magnetosphere. Journal of Geophysical Research: Space Physics, 88, 853-861. https://doi.org/10.1029/JA088iA02p00853

[19] Ruohoniemi, J.M., Greenwald, R.A., Baker, K.B. and Samson, J.C. (1991) HF Radar Observations of Pc5 Field Line Resonances in the Midnight/Early Morning MLT Sector. Journal of Geophysical Research: Space Physics, 96, 15697-15710. https://doi.org/10.1029/91JA00795

[20] Saka, O., Kitamura, T.I., Shimoizzumi, M., Araki, T., Oguti, T., Veliz, O. and Ishitsuka, M. (1988) The Effects of Non-Uniform Ionosphere on the Equatorial PC Pulsations. Journal of Geomagnetism and Geoelectricity, 40, 635-643.

[21] Schott, J.J., Kleimenova, N.G., Bitterly, J. and Kozyreva, O.V. (1998) The Strong Pc5 Geomagnetic Pulsations in the Initial Phase of the Great Magnetic Storm of March 24, 1991. Earth, Planets and Space, 50, 101-106. https://doi.org/10.5636/jgg.40.635

[22] Shinohara, M., Yumoto, K., Hosen, N., Yoshikawa, A., Tachihara, H., Saka, O., Kitamura, T.I., Trivedi, N.B., Da Costa, J.M. and Schuch, N.J. (1998) Wave Characteristics of Geomagnetic Pulsations across the Dip Equator. Journal of Geophysical Research: Space Physics, 1103, 11745-11754. https://doi.org/10.1029/97JA03067

[23] Southwood, D.J. (1974) Some Features of Field Line Resonances in the Magnetosphere. Planetary and Space Science, 22, 483-491. https://doi.org/10.1016/0032-0633(74)90078-6 